\title{
PERBANDINGAN PENGUKURAN KADAR VITAMIN C MENGGUNAKAN SPEKTROFOTOMETRI UV-VIS PADA PANJANG GELOMBANG UV DAN VISIBLE
}

\section{Comparison of Measurement The Vitamin C Level using UV-Vis Spetrophotometry at Uv and Visible Wavelength}

\author{
1*Khoirul Ngibad, ${ }^{2}$ Dheasy Herawati \\ ${ }^{1,2}$ Fakultas Ilmu Kesehatan, Universitas Maarif Hasyim Latif, Jl. Raya Ngelom Megare No.30, Ngelom, Taman, Kabupaten Sidoarjo, \\ Indonesia \\ *e-mail : khoirul ngibad@dosen.umaha.ac.id
}

\begin{abstract}
ABSTRAK
Vitamin C merupakan sumber antioksidan yang mempunyai fungsi utama untuk menghambat terjadinya suatu reaksi oksidasi dan menghambat suatu radikal bebas. Sumber vitamin $C$ dapat ditemui dalam makanan dan minuman. Penelitian ini bertujuan untuk mengetahui perbandingan pengukuran kadar vitamin C menggunakan spektrofotometer UV-Vis pada panjang gelombang UV dan Visible. Metode yang digunakan dalam penelitian ini adalah metode spektrofotometri UV-Vis. Pengukuran kadar vitamin C pada panjang gelombang UV $266 \mathrm{~nm}$ dan panjang gelombang Visible $494 \mathrm{~nm}$ dengan rentang kurva kalibrasi 0,3 sampai $0,8 \mathrm{mg} / \mathrm{L}$. Validasi metode pengukuran yang dipelajari meliputi: linearitas, batas deteksi, batas kuantisasi, dan ketelitian. Hasil penelitian menunjukkan bahwa dalam pengukuran kadar vitamin $\mathrm{C}$ pada panjang gelombang UV menghasilkan linearitas konsentrasi $0,2-0,8 \mathrm{mg} / \mathrm{L}$, batas deteksi $0,05 \mathrm{mg} / \mathrm{L}$, batas kuantisasi $0,17 \mathrm{mg} / \mathrm{L}$ dan tingkat ketelitian dengan RSD sebesar 0,2015. Di sisi lain, dalam pengukuran kadar vitamin C pada panjang gelombang Visible menghasilkan linearitas konsentrasi $0,3-0,8 \mathrm{mg} / \mathrm{L}$, batas deteksi $0,05 \mathrm{mg} / \mathrm{L}$, batas kuantisasi $0,18 \mathrm{mg} / \mathrm{L}$ dan tingkat ketelitian dengan RSD sebesar 1,0489. Dengan demikian, pengukuran kadar vitamin C pada sampel menggunakan spektrofotometer UV-Vis lebih diutamakan diukur pada panjang gelombang UV.
\end{abstract}

Kata kunci : vitamin $C$, spektrofotometri UV-Vis, panjang gelombang UV, panjang gelombang Visible

\section{ABSTRACT}

Vitamin $C$ is a source of antioxidants which has a main function to inhibit the occurrence of an oxidation reaction and inhibit a free radical. The source of vitamin $C$ can be found in food and beverage. The aim of this study is to compare the measurement of vitamin C levels using a UV-Vis spectrophotometer at UV and Visible wavelength. The method used in this study was the UV-Vis spectrophotometry method. The measurement of vitamin C levels at UV wavelength $266 \mathrm{~nm}$ and Visible wavelength $494 \mathrm{~nm}$ with a calibration curve range 0.3 to $0.8 \mathrm{mg} / \mathrm{L}$. Validation of the methods studied included: linearity, detection limits, quantization limits, and precision. The results showed that the measurement of vitamin $C$ levels at $U V$ wavelengths resulted in linearity of concentrations of $0.2-0.8 \mathrm{mg} / \mathrm{L}$, limit of detection of $0.05 \mathrm{mg} / \mathrm{L}$, limit of quantization of $0.17 \mathrm{mg} / \mathrm{L}$ and level of precision with RSD to 0.2015. On the other hand, the measurement of vitamin C levels in the Visible wavelength produced linearity from concentrations of 0.3 to $0.8 \mathrm{mg} / \mathrm{L}$, detection limit of $0.05 \mathrm{mg} / \mathrm{L}$, quantization limit of 0.18 $\mathrm{mg} / \mathrm{L}$ and the level of precision with RSD of 1.0489. Thus, determination of vitamin C levels in samples using a UV-Vis spectrophotometer was preferred to be measured at UV wavelengths.

Keyword: vitamin C, UV-Vis spectrophotometry, UV wavelength, Visible wavelength

\section{PENDAHULUAN}

Vitamin $\mathrm{C}$ atau asam askorbat dengan struktur kimia $\mathrm{C}_{6} \mathrm{H}_{8} \mathrm{O}_{6}$ dikenal sebagai sumber antioksidan terbesar yang terdapat dalam bahan makanan dan minuman. Antioksidan tersebut dapat bertindak sebagai inaktivator reaksi oksidasi dan radikal bebas (Mulyani, 2018). Kebutuhan akan vitamin C bisa didapatkan dari buah-buahan seperti jeruk, pepaya, mangga, anggur, semangka, dan lain-lain. Semakin besar kadar vitamin $\mathrm{C}$ dalam suatu buah-buhan semakin besar kemampuannya sebagai inaktivator reaksi oksidasi. 
Penentuan vitamin $\mathrm{C}$ yang terkandung di dalam sampel makanan dan minuman kemasan bisa ditentukan menggunakan metode titrimetri (Rahmawati, et al.,2016; Siti, et al., 2016) dan spektrofotometer UV-Vis (Buhari, 2010; Arny, et al.,2016;Karinda et al., 2013). Metode spektrofotometer UV-Vis mempunyai kelebihan daripada metode titrasi, yaitu memiki batas deteksi yang rendah serta memiliki tingkat akurasi dan presisi yang tinggi. Oleh karena itu, metode spektrofotometer UV-Vis banyak digunakan dalam penentuan kadar vitamin $\mathrm{C}$ dalam sampel makanan dan minuman.

Spektrofotometer UV-Vis memiliki panjang gelombang UV $200-400 \mathrm{~nm}$ dan panjang gelombang Visible 400 - $700 \mathrm{~nm}$. Pemilihan kedua panjang gelombang tersebut didasarkan pada keterbacaan absorbansi suatu analit (Pratama et al., 2018). Kadar vitamin C dapat diukur pada panjang gelombang UV $266 \mathrm{~nm}$ (Mulyani, 2018) dan pada panjang gelombang Visible $494 \mathrm{~nm}$ (Tahir, et al.,2018). Penentuan kadar vitamin C pada panjang gelombang Visible didasarkan pada terbentuknya warna komplementer yang dapat dilihat secara kasat mata oleh manusia sehingga analit perlu direaksikan dengan suatu reagen seperti ammonium molibdat. Dengan demikian, penelitian ini mempelajari perbandingan pengukuran kadar vitamin $\mathrm{C}$ menggunakan spektrofotometer UV-Vis pada panjang gelombang UV dan Visible menggunakan reagan ammonium molibdat.

\section{METODE PENELITIAN}

\section{Bahan}

Bahan-bahan yang digunakan antara lain: asam askorbat p.a, ammonium molibdat $5 \%$, asam oksalat $0,4 \%$, dan akuades.

\section{Alat}

Alat-alat yang digunakan antara lain: labu ukur, Spektrofotometer UV-Vis, kertas saring, timbangan analitik, blender, batang pengaduk, erlenmeyer, gelas kimia, pipet volume, pipet ukur, tabung reaksi, kuvet $\mathrm{UV}$, dan kuvet visible.

\section{Prosedur}

Pembuatan larutan stok asam askorbat 1000 $\mathbf{m g} / \mathbf{L}$

Sebanyak $25 \mathrm{mg}$ asam askorbat standar ditimbang dengan teliti dan dimasukkan ke dalam labu ukur 25
$\mathrm{mL}$ dilarutkan dengan asam oksalat $0,4 \%$ hingga 25 $\mathrm{mL}$.

\section{Pembuatan kurva kalibrasi}

Dalam penelitian ini, dipelajari perbandingan pengukuran kadar vitamin $\mathrm{C}$ pada panjang gelombang UV dan panjang gelombang Visible. Larutan asam askorbat $10 \mathrm{mg} / \mathrm{L}$ dipipet sebanyak 7 kali yaitu 0,$2 ; 0,3 ; 0,4 ; 0,5 ; 0,6 ; 0,7$ dan $0,8 \mathrm{~mL}$. Masing-masing dimasukkan ke dalam labu ukur 10 mL. Kemudian ditambahkan $\mathrm{H}_{2} \mathrm{SO}_{4} 5 \%$ sebanyak 4 $\mathrm{mL}$ dan dicukupkan volumenya dengan ammonium molibdat 5\% sampai batas tanda lalu dihomogenkan. Dari prosedur ini, akan diperoleh diperoleh konsentrasi 0,$2 ; 0,3 ; 0,4 ; 0,5 ; 0,6 ; 0,7$ dan $0,8 \mathrm{mg} / \mathrm{L}$. Kemudian dilakukan proses inkubasi selama 0,5 jam. Diukur serapannya dengan spektrofotometri UV-Vis pada panjang gelombang $494 \mathrm{~nm}$ dan dibuat kurva persamaan regresi linear $y=a x+b$ dan nilai koefisien korelasi yang menunjukkan linearitas kurva baku tersebut. Dalam penelitian ini, juga dipelajari pengukuran kadar vitamin $\mathrm{C}$ pada panjang gelombang UV dengan perlakuan sama dengan di atas tetapi larutan standar vitamin $\mathrm{C}$ tidak ditambah reagen dan tidak dilakukan inkubasi dengan pengukuran absorbansi dilakukan pada panjang gelombang $266 \mathrm{~nm}$.

\section{Penentuan batas deteksi (LoD) dan batas kuantitas (LoQ)}

Batas deteksi dan batas kuantitas dapat dihitung secara statistika melalui persamaan garis linear dari kurva baku. Simpangan baku atau standar dari blanko (Sy/x) ditentukan dengan cara mengukur absorbansi blanko sebanyak 20 kali ulangan.

\section{Ketelitian}

Uji ketelitian dilakukan pada konsentrasi vitamin C $0,5 \mathrm{mg} / \mathrm{L}$ baik pengukuran pada panjang gelombang UV dan panjang gelombang Visible. Pembacaan absorbansi dilakukan sebanyak 10 kali ulangan. Kemudian dihitung nilai RSD.

Keterangan :

$$
\mathrm{RSD}=\frac{\mathrm{sd}}{\text { rata-rata }} \times 100 \%
$$

sd = standar deviasi atau simpangan baku

$\mathrm{RSD}=$ relative standar deviation 
BJMLT

\section{HASIL DAN PEMBAHASAN}

\section{Validasi Metode}

\section{Pembuatan kurva baku (linearitas)}

Dalam penelitian ini, dipelajari perbandingan pengukuran kadar vitamin $\mathrm{C}$ pada panjang gelombang UV dan gelombang Visible menggunakan reagen ammonium molibdat. Tabel 1 memperlihatkan hasil pengukuran absorbansi dari beberapa larutan standar vitamin $\mathrm{C}$ mulai dari konsentrasi 0,2 sampai $0,8 \mathrm{mg} / \mathrm{L}$ pada panjang gelombang UV. Semakin besar konsentrasi larutan standar vitamin $\mathrm{C}$ semakin besar absorbansi yang dihasilkan. Hal ini menunjukkan bahwa hubungan antara konsentrasi dan absorbansi yang dihasilkan pada panjang gelombang UV adalah linear. Tingkat linearitas tersebut dibuktikan dengan nilai $\mathrm{R}^{2}$ persamaan garis linear sebesar 0,9882 (Gambar 1). Nilai $\mathrm{R}^{2}$ yang bagus adalah ketika mendekati nilai 1 .

Tabel 1. Hasil pengukuran absorbansi dalam pembuatan kurva kalibrasi pada Panjang gelombang UV

\begin{tabular}{cc}
\hline Konsentrasi vitamin C $(\mathrm{mg} / \mathrm{L})$ & Absorbansi \\
\hline 0,2 & 0,228 \\
0,3 & 0,241 \\
0,4 & 0,254 \\
0,5 & 0,261 \\
0,7 & 0,284 \\
0,8 & 0,304 \\
\hline
\end{tabular}

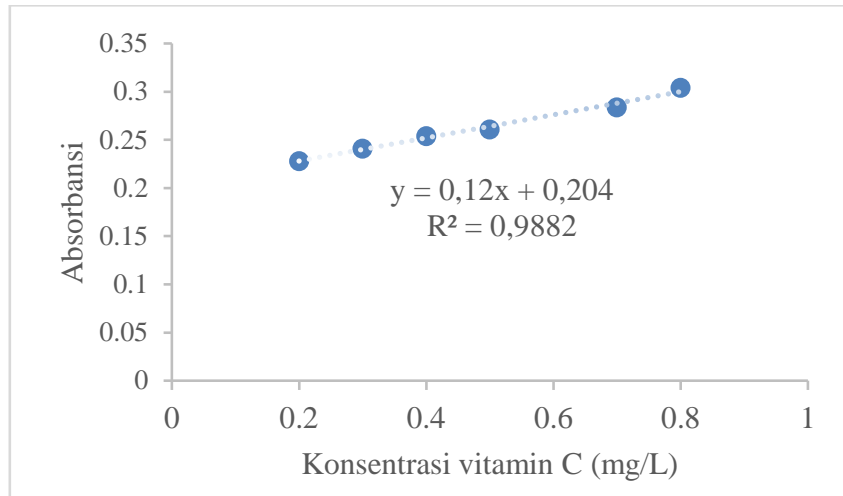

Gambar 1. Kurva kalibrasi standar vitamin C tanpa menggunakan reagen

Di sisi lain, Tabel 2 menunjukkan hasil pengukuran absorbansi dari beberapa larutan standar vitamin $\mathrm{C}$ mulai dari konsentrasi 0,3 sampai 0,8 $\mathrm{mg} / \mathrm{L}$ pada panjang gelombang Visible. Semakin besar konsentrasi larutan standar vitamin $\mathrm{C}$ semakin besar absorbansi yang dihasilkan. Hal ini juga menunjukkan bahwa hubungan antara konsentrasi dan absorbansi yang dihasilkan pada panjang gelombang Visible adalah linear dengan nilai $\mathrm{R}^{2}$ persamaan garis linear sebesar 0,8504 (Gambar 2).

Tabel 2. Hasil pengukuran absorbansi dalam pembuatan kurva kalibrasi pada gelombang Visible

\begin{tabular}{cc}
\hline Konsentrasi vitamin C $(\mathrm{mg} / \mathrm{L})$ & Absorbansi \\
\hline 0,3 & 0,065 \\
0,4 & 0,074 \\
0,5 & 0,075 \\
0,6 & 0,078 \\
0,7 & 0,079 \\
0,8 & 0,081 \\
\hline
\end{tabular}

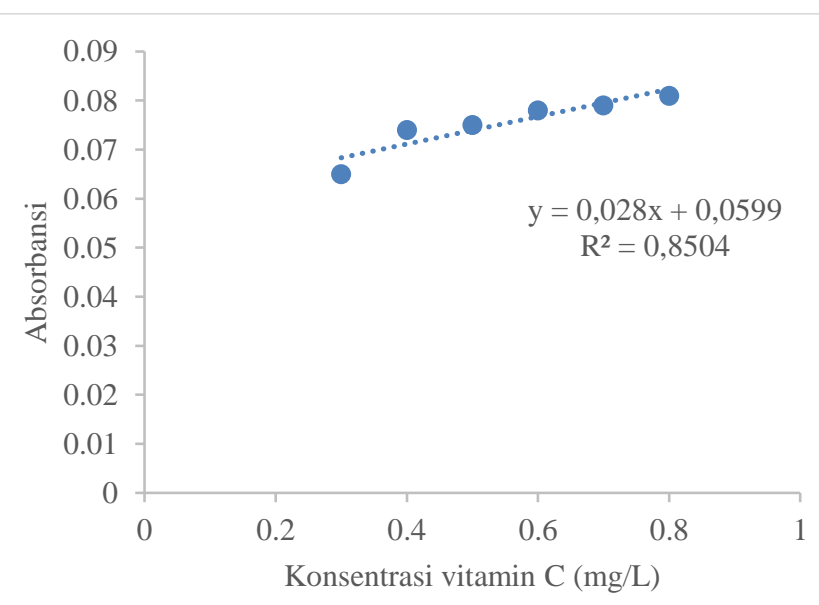

Gambar 2. Kurva kalibrasi standar vitamin C menggunakan reagen ammonium molibdat

Berdasarkan data parameter kinerja kurva kalibrasi, yang meliputi: slope, intercept, correlation determination, dan correlation coeffisien yang disajikan dalam Tabel 3 dapat diketahui bahwa slope dari pengukuran panjang gelombang UV adalah lebih besar daripada pengukuran pada panjang gelombang visible. Semakin besar slope dari persamaan garis linear semakin sensitif kinerja kurva kalibrasi tersebut. Tingkat sensitifitas suatu metode uji ditunjukkan terhadap perubahan konsentrasi. Di sisi lain, linearitas suatu metode uji dapat dilihat dari nilai correlation determination $(R)$ dan correlation coeffisien ( $r$ ) yang dihasilkan. Bedasarkan Tabel 3, dapt dilihat bahwa correlation determination $(R)$ dan correlation coeffisien ( $r$ ) yang dihasilkan pada pengukuran panjang gelombang UV adalah lebih mendekati nilai 1 daripada pengukuran pada panjang 
gelombang visible. Parameter intercept (a) dari suatu metode uji idealnya adalah nol namun penelitian ini menghasilkan nilai intercept yang tidak nol. Hal ini dapat disebabkan oleh adanya gangguan (noise) ataupun kontaminasi dalam suatu pengukuran.

Tabel 3. Perbandingan kinerja kurva kalibrasi vitamin $\mathrm{C}$ antara pengukuran pada Panjang gelombang UV dan Visible

\begin{tabular}{|c|c|c|}
\hline Parameter & $\begin{array}{c}\text { Panjang } \\
\text { gelombang UV }\end{array}$ & $\begin{array}{c}\text { Panjang } \\
\text { gelombang } \\
\text { Visible }\end{array}$ \\
\hline Slope & 0,12 & 0,028 \\
\hline $\begin{array}{c}\text { Correlation } \\
\text { Determination }(R)\end{array}$ & 0,9882 & 0,8504 \\
\hline $\begin{array}{l}\text { Correlation } \\
\text { coeffisien }(r)\end{array}$ & 0,9940 & 0,9222 \\
\hline Intercept & 0,204 & 0,0599 \\
\hline
\end{tabular}

\section{Penentuan batas deteksi (LOD) dan batas kuantitas (LOQ)}

Batas deteksi (LOD) merupakan jumlah analit terkecil dalam suatu sampel yang masih dapat dideteksi yang ditunjukkan adanya respon yang lebih signifikan dibandingkan dengan respon blanko sedangkan batas kuantitasi (LOQ) adalah jumlah analit terkecil dalam sampel yang masih dapat memenuhi kriteria cermat dan seksama (Harmita, 2012). Dalam penelitian ini, juga dilakukan penentuan batas deteksi) dan batas kuantisasi dari metode spektorfotometer UV-Vis. Penentuan batas deteksi dan kuantitasi dilakukan dengan pengukuran rasio S/N. Standar deviasi blanko ditentukan dengan cara mengukur absorbansi blanko sebanyak 20 kali. Hasil pengukuran dan perhitungan menunjukkan bahwa batas deteksi dan batas kuantitas yang diperoleh dalam pengukuran pada panjang gelombang UV sebesar $0,05 \mathrm{mg} / \mathrm{L}$ dan $0,17 \mathrm{mg} / \mathrm{L}$. Di sisi lain, hasil pengukuran dan perhitungan menunjukkan bahwa batas deteksi dan batas kuantitas yang diperoleh dalam pengukuran pada panjang gelombang Visible sebesar $0,05 \mathrm{mg} / \mathrm{L}$ dan $0,18 \mathrm{mg} / \mathrm{L}$. Apabila pengukuran menghasilkan absorbansi yang melebihi nilai LOD dan LOQ tersebut berarti masih memberikan kecermatan analisis (Lestari, Sabikis, \& Utami, 2016).

\section{Ketelitian}

Dalam penelitian ini, uji ketelitian dilakukan dengan cara mengukur absorbansi larutan standar vitamin $\mathrm{C}$ $0,5 \mathrm{mg} / \mathrm{L}$ yang diukur sebanyak 10x ulangan (Tabel 4). Ketelitian adalah salah satu parameter dalam uji validasi metode analisis yang menunjukkan tingkat keterulangan data hasil pengukuran. Penentuan ketelitian didasarkan pada hasil standar deviasi (sd) atau standar deviasi relatif. Nilai \% RSD yang diperbolehkan maksimal adalah $5 \%$ (Romsiah, Marista, \& Fatoni, 2017). Dalam penelitian ini, standar deviasi (sd) yang dihasilkan dalam pengukuran pada panjang gelombang UV sebesar 0,0005 dengan \% RSD sebesar $0,2015 \%$ sedangkan standar deviasi yang dihasilkan dalam pengukuran pada panjang gelombang Visiblesebesar 0,0007 dengan \% RSD sebesar 1,0489 \%. Dengan demikian, dapat disimpulkan bahwa uji presisi dalam penentuan vitamin $\mathrm{C}$ baik menggunakan pengukuran pada panjang gelombang UV maupun pada panjang gelombang Visible adalah telah memenuhi persyaratan.

Tabel 4. Uji ketelitian dalam pengukuran pada panjang gelombang UV dan panjang gelombang Visible

\begin{tabular}{|c|c|c|c|}
\hline \multirow[b]{2}{*}{$\mathrm{n}$} & \multirow{2}{*}{$\begin{array}{c}\text { Konsentrasi } \\
(\mathrm{mg} / \mathrm{L})\end{array}$} & \multicolumn{2}{|c|}{$\begin{array}{c}\text { Absorbansi dari hasil } \\
\text { pengukuran }\end{array}$} \\
\hline & & $\begin{array}{c}\text { Panjang } \\
\text { gelombang } \\
\text { UV } \\
\end{array}$ & $\begin{array}{c}\text { Panjang } \\
\text { gelombang } \\
\text { Visible } \\
\end{array}$ \\
\hline 1 & 0,5 & 0,261 & 0,075 \\
\hline 2 & 0,5 & 0,261 & 0,076 \\
\hline 3 & 0,5 & 0,262 & 0,074 \\
\hline 4 & 0,5 & 0,262 & 0,075 \\
\hline 5 & 0,5 & 0,261 & 0,076 \\
\hline 6 & 0,5 & 0,262 & 0,074 \\
\hline 7 & 0,5 & 0,262 & 0,075 \\
\hline 8 & 0,5 & 0,261 & 0,076 \\
\hline 9 & 0,5 & 0,262 & 0,075 \\
\hline 10 & 0,5 & 0,261 & 0,076 \\
\hline \multicolumn{2}{|c|}{ Rata-rata } & 0,2615 & 0,0752 \\
\hline \multicolumn{2}{|c|}{$\begin{array}{l}\text { Standar deviation } \\
(\mathrm{sd})\end{array}$} & 0,0005 & 0,0007 \\
\hline \multicolumn{2}{|c|}{$\begin{array}{l}\text { Relative standar } \\
\text { deviation (RSD) }\end{array}$} & 0,2015 & 1,0489 \\
\hline
\end{tabular}

\section{KESIMPULAN}

Validasi metode dalam pengukuran kadar vitamin $\mathrm{C}$ pada panjang gelombang UV menghasilkan linearitas dari konsentrasi $0,2-0,8 \mathrm{mg} / \mathrm{L}$ dengan slope 0,12 dan nilai $\mathrm{R}^{2}$ (Coefficient of determination) 0,9882. Batas deteksi yang dihasilkan dalam pengukuran kadar vitamin C pada panjang gelombang UV sebesar 
$0,05 \mathrm{mg} / \mathrm{L}$, batas kuantisasi sebesar $0,17 \mathrm{mg} / \mathrm{L}$ dan tingkat ketelitian dengan RSD sebesar 0,2015. Di sisi lain, validasi metode dalam pengukuran kadar vitamin $\mathrm{C}$ pada panjang gelombang Visible menggunakan reagen ammonium molibdat menghasilkan linearitas dari konsentrasi $0,3-0,8$ $\mathrm{mg} / \mathrm{L}$ dengan slope 0,028 dan nilai $\mathrm{R}^{2} 0,8504$. Batas deteksi yang dihasilkan dalam pengukuran kadar vitamin $\mathrm{C}$ pada panjang gelombang Visible sebesar $0,05 \mathrm{mg} / \mathrm{L}$, batas kuantisasi sebesar $0,18 \mathrm{mg} / \mathrm{L}$ dan tingkat ketelitian dengan RSD sebesar 1,0489.

\section{DAFTAR PUSTAKA}

Arny, N., Putri, A. N., Andina, L. (n.d.). Analisis Kuantitatif Vitamin C Dalam Injeksi Whitening Menggunakan Metode Spektrofotometri UvVis.

Buhari, I. 2010. Analisis Kadar Vitamin C dalam Produk Olahan Buah Salak (Salacca zalacca) secara Spektrofotometri UV-Vis. Universitas Islam Negeri Alauddin Makassar.

Harmita, H. 2012. Petunjuk pelaksanaan validasi smetode dan Cara Perhitungannya. Pharmaceutical Sciences and Research (PSR), 1(3): 117-135.

Karinda, M., Fatimawali, F., Citraningtyas, G. 2013. Perbandingan Hasil Penetapan Kadar Vitamin C Mangga Dodol dengan Menggunakan Metode Spektrofotometri UV-Vis dan Iodometri. PHARMACON, 2(1): 86-89.

Lestari, P., Sabikis, S.,Utami, P. I. 2016. Analisis Natrium Nitrit Secara Spektrofotometri Visibel Dalam Daging Burger Yang Beredar Di Swalayan Purwokerto. PHARMACY: Jurnal Farmasi Indonesia (Pharmaceutical Journal of Indonesia), 8(3).

Mulyani, E. 2018. Perbandingan Hasil Penetapan Kadar Vitamin C pada Buah Kiwi (Actinidia deliciousa) dengan Menggunakan Metode Iodimetri dan Spektrofotometri UV-Vis. Pharmauho, 3(2).

Pratama, M.R.F., Suratno, S., \& Mulyani, E. 2018. Profile of Thin-Layer Chromatography and UVVis Spectrophotometry of Akar Kuning Stem Extract (Arcangelisia flava). Borneo Journal of Pharmacy. 1(2):72-76.

Rahmawati, F., \& Hana, C. 2016. PENETAPAN Kadar Vitamin C Pada Bawang Putih (Allium Sativum, L) Dengan Metode Iodimetri. Cerata Jurnal Ilmu Farmasi (Journal of Pharmacy Science), 4(1).

Romsiah, R., Marista, S. L., \& Fatoni, A. 2017. Validasi Metode Dan Penetapan Kadar Nitrit
(No2-) Pada Sosis Sapi Curah Dan Sosis Sapi Kaleng Yang Dijual Di Swalayan Kota Palembang Secara Spektrofotometri Uv-Vis. Scientia-Journal of Pharmacy and Health, 7(2), 113-119.

Siti, N., Agustina, A., Nurhaini, R. 2016. Penetapan Kadar Vitamin C Pada Jerami Nangka (Artocarpus Heterpophyllus L.). Jurnal Farmasi Sains Dan Praktis, 2(1): 1-5.

Tahir, M., Kusuma, A. T., Ekawati, E. 2018. Analysis of Lycopene and Vitamin C Levels of Pomelo Citrus Fruit (Citrus maxima (Burm) Merr) Red $\mathrm{n}$ White Varieties From South Sulawesi. JCPS (Journal of Current Pharmaceutical Sciences), 2(1): 125-130. 